\title{
Adenoid Hipertrofili Çocukların Değerlendirilmesi: Sefalografi ve Endoskopi'nin Karșılaștırılması
}

\author{
Evaluation of Children With Adenoid Hypertrophy: Cephalogram versus Endoscopy
}

Selmin Karataylı-Özgürsoy' ${ }^{1}$, Selçuk Mülazımoğlu², Metin Nuri Akıner²

' Dr. Sami Ulus Kadın Hastalıkları ve Doğum ve Çocuk Hastalıkları
EAH, Kulak Burun Boğaz ABD, Ankara, Türkiye
2 Ankara Üniversitesi Tıp Fakültesi, Kulak Burun Boğaz ABD, Ankara,
Türkiye

Geliș tarihi: 13.02.2014 Kabul tarihi: 20.04.2014

İletișim

Dr. Selmin Karatayli-Ozgursoy

Cep: 0 (532) 6159621

E-posta: selminkrt@hotmail.com

Ankara Üniversitesi Tıp Fakültesi, Kulak Burun Boğaz ABD, Ankara, Türkiye

Amaç: Adenoidektomi, kulak burun boğaz hekimleri tarafından en sık uygulanan operasyonlardan biridir. 'Adenoid hipertrofi' tanısı koyabilmek için palpasyon, ayna ile görüntüleme, akustik rinometri, rinomanometri, nazal endoskopi ve radyolojik görüntüleme yöntemlerini de içeren bazı metodlar kullanılabilmektedir. Biz bu çalıșmada, çocuk hastalarda lateral sefalografide adenoid/nazofarenks $(\mathrm{A} / \mathrm{N})$ oranının etkinliğini, endoskopik muayene sonuçlarımız ile karșılaștırmayı hedefledik.

Gereç ve Yöntem: 2009 Temmuz-2013 Ocak arasında iki hastanenin KBB ( Kulak Burun Boğaz ) polikliniğine bașvuran 1-16 yaș arası çocuk hastalar dahil edildi. Bütün hastalar horlama, ağzı açık uyuma, apne, ağız kuruluğu gibi adenoid hipertrofisi semptomları sebebi ile pediatri bölümünce KBB'ye konsülte edilen, ve pediatri bölümünce değerlendirilme așamasında zaten lateral grafi çekilmiș olan hastalardı. Hastaların endoskopik ve lateral sefalometrik bulguları arasındaki ilișkilerin incelenmesinde Spearman'ın korelasyon katsayısı kullanıldı.

Bulgular: Yas grupları 0-6 yas ve 6 yas üstü; veya $0-4$ yaș, $5-9$ yas ve 10 yas ve üstü ( $\geq 10$ ) olarak kategorize edildiğinde, $\mathrm{A} / \mathrm{N}$ oranı ve endoskopik muayenede adenoid vejetasyon obstrüksiyon yüzdeleri arasındaki ilișkinin her yaș grubunda istatistiksel olarak anlamlı olduğu gözlendi.

Sonuç: Sonuç olarak, nazal endoskopi, 'adenoid hipertrofi' tanısı koymak için günlük uygulamamızda altın standart olarak yer alan bir metoddur. Nazal endoskopi uygulanamayan veya endoskopi bulgularının yetersiz olduğu seçilmiș olgularda, lateral sefalografide $\mathrm{A} / \mathrm{N}$ oranı güvenilir bir șekilde uygulanabilir.

Anahtar Sözcükler: Adenoid, adenoid hipertrofi, lateral sefalografi, nazal endoskopi, A/N oranı

Aim: Adenoidectomy is one of the most frequent operations performed by otolaryngologists. In order to diagnose 'adenoid hypertrophy', some methods have been used including palpation, mirror usage for nasopharyngeal view, acoustic rhinometry, rhinomanometry, nasal endsocopy, and radiological images. In this study, we aimed to assess the correlation between adenoid/nasopharynx $(\mathrm{A} / \mathrm{N})$ ratio in lateral cephalography and nasopharyngeal obstruction in endoscopical view in pediatric patients.

Materials and Methods: Pediatric patients with the age range of 1 to 16 who applied to otolaryngology outpatient clinics in two institutions between July 2009 and January 2013 were included. All of the patients were referred by pediatricians and had already undergone lateral cephalography with the complaints of open-mouth sleeping, snoring, apnea, dry mouth. Percentage of nasopharyngeal obstruction in endoscopic view and $\mathrm{A} / \mathrm{N}$ ratio in lateral cephalography were compared by using Sperman's correlation coefficient.

Results: When the age groups are categorized to $0-6$ and $6-16$, or $0-4,5-9$ and $10-16$, in all age groups the association between nasopharyngeal obstruction in endoscopic view and $A / N$ ratio in lateral cephalography was statistically significant.

Conclusion: In conclusion, nasal endoscopy is the golden standard for the diagnosis of adenoid hypertrophy. In patients who can not tolerate this procedure or if the endoscopic view is not clear enough, $\mathrm{A} / \mathrm{N}$ ratio in lateral caphalography is a reliable method.

Key Words: Adenoid, adenoid hypertrophy, lateral cephalography, nasal endoscopy, A/N ratio

Adenoidektomi, kulak burun boğaz hekimleri tarafindan en sik uygulanan operasyonlardan biridir. Adenoid dokusunun büyüklügünün ve nazofarengeal obstrüksiyon derecesinin saptanmas1, adenoidektomi yapılacak hastaların seçiminde zor fakat önemlidir (1).
Anamnez ve fizik muayene önemlidir, ancak subjektiftir $(2,3)$. Bu nedenle 'adenoid hipertrofi' tanisi koyabilmek için palpasyon, ayna ile görüntüleme, akustik rinometri $(4,5)$, rinomanometri $(1,6)$, nazal endoskopi $(7,8)$ ve radyolojik görüntüleme yöntemlerini (9-12) de 
içeren bazı metodları uygulamak gerekebilmektedir. Lateral sefalografide, adenoid dokusunun büyüklüğünü ölçmek amacıyla, adenoid/nazofarenks (A/N) oran1; Fujioka ve arkadaşları tarafindan 1979'da tarif edilmiştir (10). Biz bu çalışmada, 143 hastada $\mathrm{A} / \mathrm{N}$ oranının etkinliğini, endoskopik muayene sonuçları ile karşılaştırmayı hedefledik.

\section{MATERYAL ve METOD}

Çalışmaya 2009 Temmuz-2013 Ocak arasinda Dr. Sami Ulus Kadın Doğum ve Çocuk Hastalıkları Eğitim ve Araştırma Hastanesi ve Ankara Üniversitesi Tip Fakültesi İbn-i Sina Hastanesi KBB polikliniğine başvuran 1-16 yaş arası çocuk hastalar dahil edildi. Bütün hastalar horlama, ağz1 açı uyuma, apne, ağız kuruluğu gibi adenoid hipertrofisi semptomlar1 sebebi ile pediatri bölümünce KBB'ye konsülte edilen, ve pediatri bölümünce değerlendirilme aşamasında zaten lateral grafi çekilmiş olan hastalardi.
Kooperasyon kurulması mümkün olmayan çocuklar, kanama eğilimi, diyabet, hipertansiyon gibi ek hastalığ1 olan hastalar, ek intranasal patoloji saptanan hastalar; üst solunum yolu enfeksiyonu geçiren, nazal akıntısı olan ve sekresyon nedeniyle koananin net değerlendirilemediği hastalar çalışma dıșinda tutuldu.

Hastaların hepsine fleksibl nazal endoskopi uyguland1 ve adenoid vejetasyonun endoskopide koanal obsrüksiyon yüzdeleri not edildi. Ayrıca başvuru sırasında çekilmiş olan lateral kafa grafilerindeki Adeniod/Nazofarenks yüzdesi, Fujioka'nun tarif ettiği şekilde (10) hesapland1 ve not edildi. Hastaların endoskopik ve lateral sefalometrik bulguları arasındaki ilişkilerin incelenmesinde Spearman'in korelasyon katsayısı kullanıldı. Bu çalışmayı yürütebilmek için Ankara Üniversitesi Tip Fakültesi Klinik Araştırmalar Etik Kurulu onayı alındı ve bütün hastalara ve ebeveynlerine bilgi verilerek aydınlatılmış onamları alındi.

\section{SONUÇLAR}

Çalışmaya dahil edilme kriterlerini karşılayan; Dr. Sami Ulus Kadın Doğum ve Çocuk Hastalıkları Eğitim ve Araştırma Hastanesi KBB polikliniği'ne başvuran 123 hasta ve Ankara Üniversitesi KBB polikliniği'ne başvuran 20 hasta olmak üzere toplam 143 hasta değerliendirmeye alındı. Bir ve 16 yaş arasında (yaş ortalaması 6.2) 87 erkek $56 \mathrm{k} 1 \mathrm{z}$ hasta mevcuttu. K1z ve erkek cinsiyette hastaların lateral kafa grafilerindeki Adenoid/Nazofarenks yüzdelleri ve fleksibl endoskopi görünttüsündeki obstrüksiyon yüzdeleri Tablo 1 de özetlendi. Hastallardan elde edilen adenoid vejetasyonun endoskopide koanay1 kaplama yüzdeleri ile lateral grafilerinde nazofarenksi doldurma yüzdeleri arasındaki ilişkinin incelemmesinde Spearman korelasyon katsayısı kullanıldı, buna göre $\mathrm{r}=$ 0.817 bulundu, iki değişken arasındaki ilişkinin istatistiksel olarak da anlamlı olduğu gözlendi $(\mathrm{p}<0.001)$ (Şekil 1).
Tablo 1. KIz ve erkek cinsiyette lateral grafide $A / N$ ve fleksibl endoskopide adenoid yüzdeleri

\begin{tabular}{llll} 
& Yaș & Lateral grafi & Fleksibl endoskopi \\
Kız & & & \\
\hline Ortalama & 6,09 & 72,50 & 70,09 \\
Median & 6 & 80 & 80 \\
Min & 1 & 30 & 20 \\
Max & 16 & 90 & 90 \\
Erkek & & & \\
\hline Ortalama & 5,83 & 67,07 & 67,41 \\
Median & 6 & 80 & 80 \\
Min & 1 & 20 & 20 \\
Max & 14 & 95 & 90 \\
Toplam & & & \\
\hline Ortalama & 5,93 & 69,20 & 68,46 \\
Median & 6 & 80 & 80 \\
Min & 1 & 20 & 20 \\
Max & 16 & 95 & 90
\end{tabular}

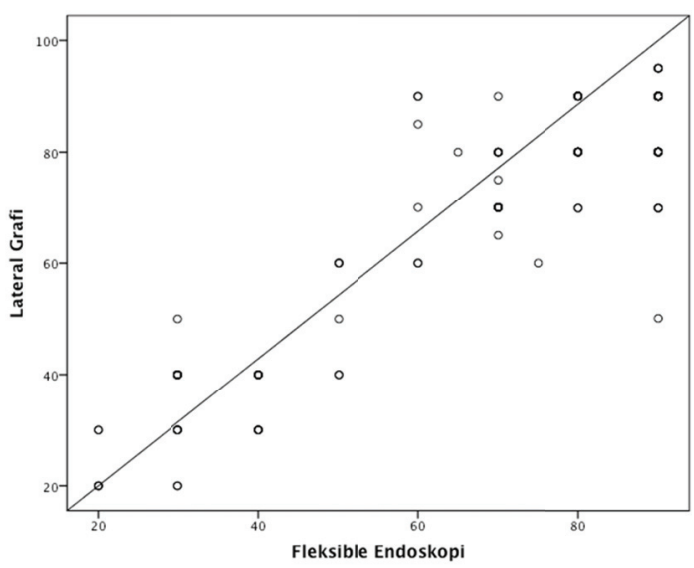

Şekil 1. Lateral kafa grafisi ve fleksibl endoskopideki adenoid yüzdeleri dağılım grafiği 
Kız ve erkek cinsiyetindeki hastaların adenoid yüzdeleri arasındaki ilișki ayrı ayrı incelendiğinde Spearman korelasyon katsayısı kız cinsiyet için $\mathrm{r}$ $=0.801$, erkek cinsiyet için $r=0,834$ olarak bulundu, her iki gruptaki değişkenler arasındaki ilişkinin istatistiksel olarak da anlamlı olduğu gözlendi $(\mathrm{p}<0.001)($ Şekil 2)

Yaş grupları kategorize edildiğinde; 6 yaş alt1 $(<6)$ grubun (Spearman korelasyon katsayıs1 $\mathrm{r}=0,638)$; ve 6 yaş ve üstü $(\geq 6)$ grubun (Spearman korelasyon katsayis1 $\mathrm{r}=0,906)$ adenoid vejetasyonun endoskopide koanayı kaplama yüzdeleri ile lateral grafilerinde nazofarenksi doldurma yüzdeleri arasındaki iliski incelendiğinde değișkenler arasındaki ilişkinin her iki grupta da istatistiksel olarak anlamlı olduğu gözlendi $(\mathrm{p}<0.001)$. Yaş grupları $0-4$ yaş (Spearman korelasyon katsayis1 $\mathrm{r}=$ 0,704) 5-9 yaş (Spearman korelasyon katsayısı $r=0,837$ ) ve 10 yaş ve üstü $(\geq 10) \quad$ (Spearman korelasyon katsayıs1 $r=0,880$ ) olarak kategorize edildiğinde ise adenoid vejetasyon yüzdeleri arasındaki ilişkinin yine her üç grupta da istatistiksel olarak anlamlı olduğu gözlendi $(\mathrm{p}<0.001)$ (Tablo 2).

Lateral kafa grafisi ve fleksibl endoskopide adenoid yüzdeleri $\% 0$ -
39 hafif, \%40-69 orta ve \%70-100 ağır olarak kategorize edildiğinde kategoriler arasındaki ilişkinin (Spearman korelasyon katsayıs1, r = $0.885)$ istatistiksel olarak da anlamlı olduğu görüldü $(p<0.001)$. Lateral kafa grafisi ve fleksibl endoskopide adenoid yüzdeleri kategorize edildiğinde hasta dağıllımları ve toplam hasta populasyonu içerisindeki yüzdeleri Tablo 3 te özetlendi. Cinsiyet ve yaş grupları kategorize edildiğinde, lateral kafa grafisi ve fleksibl endoskopideki adenoid vejetasyon yüzdeleri kategorileri arasındaki ilişkinin istatistiksel olarak da anlamlı olduğu görüldü $(\mathrm{p}<0.001)$ (Tablo 4).

Tablo 2. Yaş grupları kategorize edildiğinde lateral kafa grafisi ve fleksible endoskopi adenoid yüzdeleri ilişkisi

\begin{tabular}{llll} 
Yaş & $N$ & $\mathrm{r}$ (Spearman's rho) & $\mathrm{p}$ \\
\hline$<6$ & 70 & 0,638 & $\mathrm{p}<0.001$ \\
$\geq 6$ & 73 & 0,906 & $\mathrm{p}<0.001$ \\
\hline $0-4$ & 54 & 0,704 & $\mathrm{p}<0.001$ \\
$5-9$ & 72 & 0,837 & $\mathrm{p}<0.001$ \\
$\geq 10$ & 17 & 0,880 & $\mathrm{p}<0.001$ \\
\hline
\end{tabular}

Tablo 3. Lateral kafa grafisi ve fleksible endoskopide adenoid yüzdeleri kategorize edildiğinde dağılım

\begin{tabular}{|lll|rrr|r|}
\hline & & & \multicolumn{3}{|c|}{ Fleksible Endsokopi } & \multicolumn{2}{l|}{ Total } \\
& & & Hafif & Orta & Ağır & \\
\hline Lateral & & & & & \\
Grafi & Hafif & Say1 & 11 & 4 & 0 & 15 \\
& & $\%$ & $7,70 \%$ & $2,80 \%$ & $0,00 \%$ & $10,50 \%$ \\
\cline { 2 - 7 } & Orta & Say1 & 12 & 15 & 3 & 30 \\
& & $\%$ & $8,40 \%$ & $10,50 \%$ & $2,10 \%$ & $21,00 \%$ \\
\cline { 2 - 7 } & Ağır & Say1 & 0 & 5 & 93 & 98 \\
& & $\%$ & $0,00 \%$ & $3,50 \%$ & $65,00 \%$ & $68,50 \%$ \\
\hline Total & & Say1 & 23 & 24 & 96 & 143 \\
& & $\%$ & $16,10 \%$ & $16,80 \%$ & $67,10 \%$ & $100,00 \%$ \\
\hline
\end{tabular}

Tablo 4. Cinsiyet ve yaş kategorize edildiğinde adenoid yüzdeleri kategorileri ile ilişkisi

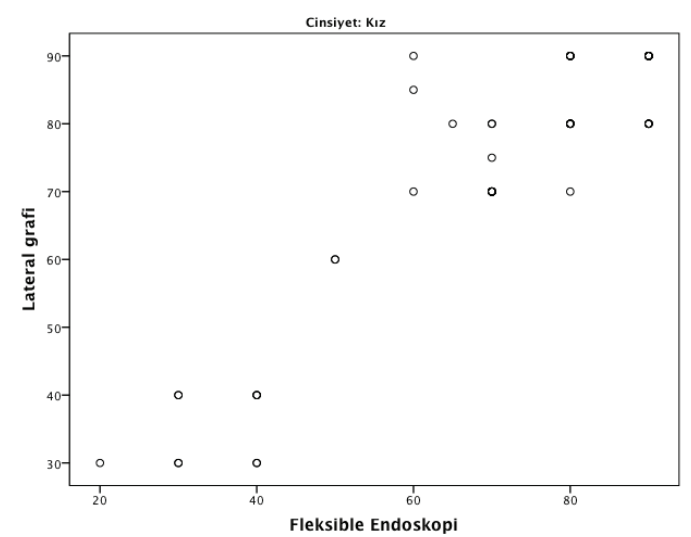

\begin{tabular}{llll} 
Kategori & $N$ & $\mathrm{r}($ Spearman's rho) & $\mathrm{p}$ \\
\hline K1z & 56 & 0,849 & $\mathrm{p}<0.001$ \\
Erkek & 87 & 0,899 & $\mathrm{p}<0.001$ \\
\hline$<6$ yaş & 70 & 0,826 & $\mathrm{p}<0.001$ \\
$\geq 6$ yaş & 73 & 0,893 & $\mathrm{p}<0.001$ \\
\hline 0-4 yaş & 54 & 0,824 & $\mathrm{p}<0.001$ \\
5-9 yaş & 72 & 0,878 & $\mathrm{p}<0.001$ \\
$\geq 10$ yaş & 17 & 0,932 & $\mathrm{p}<0.001$
\end{tabular}

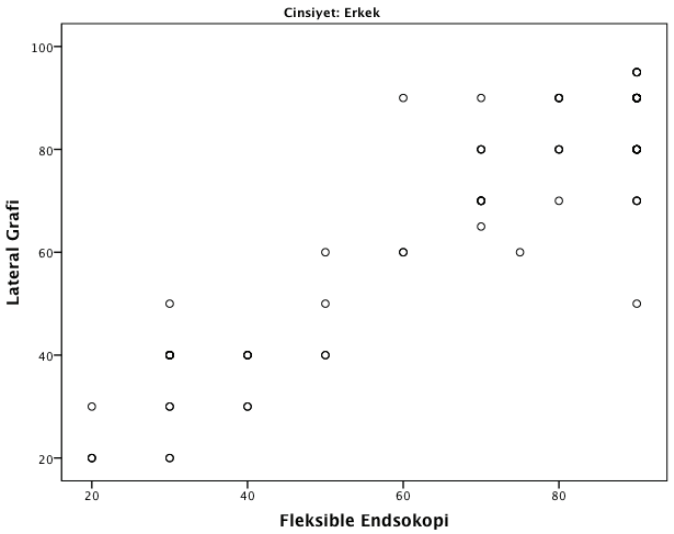

Şekil 2. Kız ve erkek cinsiyette lateral kafa grafisi ve fleksibl endoskopi adenoid yüzdeleri dağılım grafi 


\section{TARTISTMA}

Adenoid dokusunun büyüklüğünü veya adenoid-nazofarenks ilişkisini değerlendirebilmek için en basit, objektif, minimal invaziv ve de güvenilir yöntem aranmaktadır $(3,5$, 10, 12-15). Nazal endoskopi bu amaçla uygulanan 'altın standart' yöntem olarak kabul edilmektedir (16). Nazal endoskopi, uygun şartlarda ve uygun endoskop kullanıldığında güvenilir, güvenli, kolay tolere edilen ve dinamik bir diagnostik metoddur (17). Doğru ve objektif sonuçlar verir $(7,14,18,19)$. Nazal endoskopik görüntü, çeşitli metodlarla değerlendirilebilir. Clemens ve arkadaşları (20) \% 0'dan $\%$ 100'e kadar derecelendirilen bir koanal obstrüksiyon sistemini, 1'den 4'e kadar kodlayan bir sistem geliştirdiler. Benzer şekilde Çengel ve Akyol (21) ile Chisholm ve arkadaşları (16) endoskopik görüntüyü temel alan koanal obstrüksiyon değerlendirmesi yaptılar. Ancak, Chien ve arkadaşları (22) bilgisayar programı yardımı ile elde edilen dijital görüntülerde adenoid-koana oranını tanımlayarak en objektif ölçüm metodunu geliştirdiler. Biz de, bu çalışmada Chien'le benzer endoskopik değerlendirme metodunu kayıt almadan uyguladik.

Lateral sefalografi, günlük pratikte, adenoidi değerlendirmek için en sık kullanılan görüntüleme yöntemidir. 1979'da Fujioka ve arkadaşları adenoid büyüklügüünü ölçmede standardizasyon sağlamak için $\mathrm{A} / \mathrm{N}$ oranını tanımladılar(10). Cohen ve Konak (9) 1985'te adenoid büyüklüğünü, yumuşak damak kalınlığı ile karşılaştırarak; küçük (hava yolu yumuşak damaktan dar değil); orta (hava yolu yumuşak damaktan dar ama kalınlığın yarısından geniş) ve büyük (yumuşak damak kalınlığının yarısından da dar) olarak sınıflandırmıştır. Lateral sefalografinin en önemli dezavantaj1 radyasyon (5) ve anatomik yapiların süperpozisyonudur (23). Yumuşak doku görüntülerinin pozisyonel değişikliklerden ve solunum hareketlerinden etkilenebileceği rapor edilmiştir (24). Ancak A/N oran1 horizontal veya vertikal pozisyon değişikliklerinden etkilenmemektedir (25). Çünkü bu metodda tek kullanılan yumuşak doku görüntüsü, adenoid konveksitesidir. Diğer parametreler, kemik yapıların gölgeleri ile hesaplanmaktadır. Bu bakımdan A/N oraninin süperpozisyon veya pozisyonel değişikliklerden etkilenme riski çok azdır. 2007 IRCP (Uluslararası Radyasyondan Koruma Komitesi) raporunda, lateral sefalogramı da içeren tüm dental radyogramların, düşünüldüğünden daha fazla radyasyona sebebiyet verdiği ve mümkünse klinisyenlerin bu yöntemlerden daha az yararlanmaları gerektiği bildirilmiştir (26). Lateral sefalogramin sebep olduğu radyasyon (PSP) 5,6 $\mu \mathrm{Sv}$ olarak bildirilmiş, bu radyasyondan en çok tükrük bezlerinin etkilendiği rapor edilmiştir. Adenoidektomi kararı vermeden önce çocukların mükerrer kereler adenoid muayenesinden geçtiği göz önüne alınırsa, çocuk yaşta ve her seferinde bu radyasyona maruziyet kalmamaları açısından, çocuklara lateral sefalogram, sadece fleksibl endoskopinin yapılamadığ1 veya endoskopinin yeterli bulgu vermediği vakalarda uygulanmalidir.

Elwany (27), 1987'de yaptığ1 çalışmada, adenoid hipertrofili hastalarda $\mathrm{A} / \mathrm{N}$ oranının, hem klinik değerlendirme skorları ile hem de postoperatif ölçülen adenoid dokusu ağırlıkları ile korele olduklarını rapor etmiştir. Çaylaklı ve arkadaşları (17), yaptıkları çalışmada, A/N oranının fleksibl endoskopideki koanal obstruksiyon oranı ile korele olduğunu bulmuşlardır. Bu çalışmada bizim sonuçlarımız da her yaş kategorisinde bu korelasyonu doğrulamaktadır.

Sonuç olarak, nazal endoskopi, 'adenoid hipertrofi' tanısı koymak için günlük uygulamamızda altın standart olarak yer alan bir metoddur. Nazal endoskopi uygulanamayan veya endoskopi bulgularının yetersiz olduğu seçilmiş olgularda, lateral sefalografide $\mathrm{A} / \mathrm{N}$ oranı güvenilir bir şekilde uygulanabilir. 


\section{KAYNAKLAR}

1. Parker AJ, Maw AR, Powell JE. Rhinomanometry in the selection for adenoidectomy and its relation to preoperative radiology. International journal of pediatric otorhinolaryngology. 1989; 17: 155-161.

2. Maw AR, Jeans WD, Fernando DC. Inter-observer variability in the clinical and radiological assessment of adenoid size, and the correlation with adenoid volume. Clinical otolaryngology and allied sciences. 198; 6: 317-322.

3. Hibbert J, Stell PM, Wright A. Value of physical signs in the diagnosis of enlarged adenoids. Clinical otolaryngology and allied sciences. 1980; 5: 191-194.

4. Riechelmann H, O'Connell JM, Rheinheimer MC. et al. The role of acoustic rhinometry in the diagnosis of adenoidal hypertrophy in pre-school children. Eur J Pediatr. 1999; 158: 38-41.

5. Cho JH, Lee DH, Lee NS.et al. Size assessment of adenoid and nasopharyngeal airway by acoustic rhinometry in children. The Journal of laryngology and otology. 1999; 113: 899905.

6. Mostafa B. Detection of adenoidal hypertrophy using acoustic rhinomanometry. European Archives of Oto-Rhino-Laryngology. 1997; 254: $27-$ 29.

7. Wormald PJ, Prescott CA. Adenoids: comparison of radiological assessment methods with clinical and endoscopic findings. The Journal of laryngology and otology. 1992; 106: 342-344.

8. Wang DY, Clement P, Kaufman L, et al. Fiberoptic examination of the nasal cavity and nasopharynx in children. Acta oto-rhino-laryngologica Belgica. 1991; 45: 323-329.

9. Cohen D, Konak S. The evaluation of radiographs of the nasopharynx. Clinical otolaryngology and allied sciences. 1985; 10: 73-78.

10. Fujioka M, Young LW, Girdany BR. Radiographic evaluation of adenoidal size in children: adenoidal-nasopharyngeal ratio. AJR American journal of roentgenology. 1979; 133: 401-404.

11. Crepeau J, Patriquin HB, Poliquin JF, et al. Radiographic evaluation of the symptom-producing adenoid. Otolaryngology--head and neck surgery : official journal of American Academy of Otolaryngology-Head and Neck Surgery. 1982; 90: 548-554.

12. Johannesson S. Roentgenologic investigation of the nasopharyngeal tonsil in children of different ages. Acta radiologica: diagnosis. 1968; 7: 299-304.

13. Hibbert J, Stell PM. A radiological study of the adenoid in normal children. Clinical otolaryngology and allied sciences. 1979; 4: 321-327.

14. Paradise JL, Bernard BS, Colborn DK.et al. Assessment of adenoidal obstruction in children: clinical signs versus roentgenographic findings. Pediatrics. 1998; 101: 979-986.

15. Wang DY, Bernheim N, Kaufman L.et al. Assessment of adenoid size in children by fibreoptic examination. Clinical otolaryngology and allied sciences. 1997; 22: 172-177.

16. Chisholm EJ, Lew-Gor S, Hajioff D.et al. Adenoid size assessment: a comparison of palpation, nasendoscopy and mirror examination. Clinical otolaryngology: official journal of ENTUK; official journal of Netherlands Society for Oto-Rhino-Laryngology \& Cervico-Facial Surgery. 2005; 30: 39-41.

17. Caylakli F, Hizal E, Yilmaz I, et al. Correlation between adenoidnasopharynx ratio and endoscopic examination of adenoid hypertrophy: a blind, prospective clinical study. International journal of pediatric otorhinolaryngology. 2009; 73: 1532.

18. Kindermann CA, Roithmann R, Lubianca Neto JF. Sensitivity and specificity of nasal flexible fiberoptic endoscopy in the diagnosis of adenoid hypertrophy in children. International journal of pediatric otorhinolaryngology. 2008; 72: 63-67.
19. Yilmaz I, Caylakli F, Yilmazer C, et al. Correlation of diagnostic systems with adenoidal tissue volume: a blind prospective study. International journal of pediatric otorhinolaryngology. 2008; 72: 1235-1240.

20. Clemens J, McMurray JS, Willging JP. Electrocautery versus curette adenoidectomy: comparison of postoperative results. International journal of pediatric otorhinolaryngology. 1998; 43: 115-122.

21. Cengel S, Akyol MU. The role of topical nasal steroids in the treatment of children with otitis media with effusion and/or adenoid hypertrophy. International journal of pediatric otorhinolaryngology. 2006; 70: 639-645.

22. Chien CY, Chen AM, Hwang CF.et al. The clinical significance of adenoidchoanae area ratio in children with adenoid hypertrophy. International journal of pediatric otorhinolaryngology. 2005; 69: 235-239.

23. Vogler RC, Ii FJ, Pilgram TK. Agespecific size of the normal adenoid pad on magnetic resonance imaging. Clinical otolaryngology and allied sciences. 2000; 25: 392-395.

24. Britton P. Effect of respiration on nasopharyngeal radiographs when assessing adenoidal enlargement. The Journal of Laryngology \& Otology. 1989; 103: 71-73.

25. Mahboubi S, Marsh RR, Potsic WP.et al. The lateral neck radiograph in adenotonsillar hyperplasia. International journal of pediatric otorhinolaryngology. 1985; 10: 67-73.

26. Ludlow JB, Davies-Ludlow LE, White SC. Patient risk related to common dental radiographic examinations: the impact of 2007 International Commission on Radiological Protection recommendations regarding dose calculation. J Am Dent Assoc. 2008; 139: 1237-1243.

27. Elwany S. The adenoidalnasopharyngeal ratio (AN ratio). Its validity in selecting children for adenoidectomy. The Journal of laryngology and otology. 1987; 101: 569573. 
